\title{
Article
}

\section{Delusions and Personal Autonomy}

\author{
Ayob, Gloria Leila
}

Available at http://clok.uclan.ac.uk/25449/

Ayob, Gloria Leila ORCID: 0000-0001-5374-2161 (2019) Delusions and Personal Autonomy. Journal of Applied Philosophy, 36 (5). pp. 737-754. ISSN 0264-3758

It is advisable to refer to the publisher's version if you intend to cite from the work. http://dx.doi.org/10.1111/japp.12346

For more information about UCLan's research in this area go to http://www.uclan.ac.uk/researchgroups/ and search for < name of research Group>.

For information about Research generally at UCLan please go to http://www.uclan.ac.uk/research/

All outputs in CLoK are protected by Intellectual Property Rights law, including Copyright law. Copyright, IPR and Moral Rights for the works on this site are retained by the individual authors and/or other copyright owners. Terms and conditions for use of this material are defined in the policies page.

\section{CLoK}

Central Lancashire online Knowledge www.clok.uclan.ac.uk

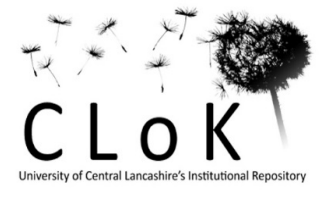


Title of paper: Delusions and Personal Autonomy

Name of author: Dr Gloria Sibson Ayob

Main institutional affiliation:

Faculty of Health and Wellbeing, University of Central Lancashire

Address for correspondence:

Dr Gloria Sibson Ayob

Senior Lecturer in Philosophy and Mental Health

Faculty of Health and Wellbeing

University of Central Lancashire

Preston PR1 2HE

United Kingdom

Email address: GLAyob@uclan.ac.uk

Abstract of paper:

This paper will examine the claim that personal autonomy is impaired by a paradigmatic instance of serious psychopathology-namely, the condition of being delusional-in light of the hierarchical conception of personal autonomy. This conception of personal autonomy aims at yielding value-neutral judgements about freedom and self-governance. I will argue that when viewed from the perspective of this specific conception of autonomy, delusions do not necessarily impair an agent's personal autonomy. In order to establish this claim, I will probe the general idea that delusional subjects are beset by a mental disease that is rationally incapacitating, to which the hierarchical theorist might appeal. I argue that, understood within the parameters set by the commitment to value neutrality, this idea fails to provide support for the claim that delusion necessarily impairs personal autonomy. One contribution this paper makes to the effort of understanding how delusion impairs personal autonomy is to help us pinpoint the ways in which our value commitments inform our judgements of impaired personal autonomy in delusional agents.

Word count: 9336 (excluding endnotes), 10276 (including endnotes) 


\section{Delusions and Personal Autonomy}

\section{Introduction}

This essay will examine the claim that personal autonomy is impaired by a paradigmatic instance of serious psychopathology-namely, the condition of being delusional-in light of the commitment to sustain a value-neutral understanding of personal autonomy. This commitment is most commonly discharged by employing the hierarchical or reflective-endorsement conception of personal autonomy. Central to this conception is a picture of the autonomous agent as one who reflectively endorses or disavows her mental states (taken to include volitional, affective, and cognitive states), and whose standing as a self-governing agent derives precisely from this act of reflective endorsement. The reflective stance adopted by the agent towards her mental states is shaped by what she values, and these values are taken to determine who she is in a deep and interesting sense, such that both the mental states that are endorsed and the endorsing stance itself are understood to be expressions of the agent's real or true self. ${ }^{1}$ Set against this are the mental states that aren't endorsed and which may be explicitly disavowed by the agent: any exercise of agency that originates from a mental state of this kind fails to count as autonomous, according to this conception of selfgovernance. ${ }^{2}$ Crucially, it is in terms of the agent's own perspective-rather than by reference to objective normative standards - that the hierarchical theorist conceives of personal autonomy. The hierarchical conception thus regards agents as the principal-if not ultimate-authority with regard to assessments of their own self-governance. In this way, it is hoped that value-neutrality is maintained in judgements about personal autonomy.

Based upon the hierarchical conception of personal autonomy, serious psychopathology is thought to impair our capacity to direct our own lives in accordance with our values in one of two ways: first, a person's agency is seen to be controlled by affective and volitional states deemed pathological (as in the case of the unwilling addict), rather than being governed by what she reflectively endorses; or second, the agent's reflective stance itself is seen to be controlled by mental illness, rather than by inner personal reflection informed by the agent's true values. ${ }^{3}$ Both versions of the threat presume that a meaningful distinction can be drawn between the real self and the elements of illness that appear in the agent's psychological architecture. However, in the former version of the threat, the agent is not yet estranged by mental illness from her 'true values', the values to which her real self is committed. She finds herself incapable of living in accordance with these values, but she knows what they are and remains committed to trying to steer her life accordingly. By contrast, in the second version of the threat, the agent is taken to be estranged from her real self in a more radical way: the mental illness takes over the agent entirely, producing not just pathological experiences but distorting any reflective stance the agent may adopt towards those experiences. It is the claim of estrangement in the latter version of the threat that will concern me here, and my focus will be on delusions specifically.

That mental states deemed delusional are not universally disavowed by their subjects is unsurprising in light of the possibility of radical estrangement. But what is surprising-and more problematic for the autonomy theorist committed to value-neutrality-is that there are agents who reflectively endorse experiences that are deemed delusional, who take these experiences to define their sense of self over an extended period of time (sometimes even a lifetime), thus spanning both periods in which they are psychotic and periods in which they are not. It is difficult to hold, in the latter phase, that the psychotic state distorts the agent's entire perspective since the agent reflectively endorses his delusional experiences in a clear sighted (i.e. non-psychotic) state. ${ }^{4}$ Cases like this challenge the assumption that an agent will necessarily retrospectively disavow the values and the experiences that 
guided him whilst psychotic, therein precluding the possibility of always being able to appeal to agents' clear sighted reflective endorsements and disavowals to shed light on how delusions impair personal autonomy.

Given this difficulty, and in the hope of upholding in value-neutral terms the claim that delusions overcome the agent's entire perspective-thereby necessarily undermining his autonomous standing-the autonomy theorist might seek instead to supplement the hierarchical conception of personal autonomy by appealing to the general idea that delusional subjects are beset by a mental disease that is rationally incapacitating. The aim of this paper is to evaluate this proposal. The discussion will proceed by surveying the most prominent ways of connecting the concepts of delusion and impaired autonomy in general terms, as follows: first by reference to the notion of disease, then to the notion of rational incapacity, and finally to the notion of anomalous experience. In each case, the guiding idea is that delusions - in virtue of being a disease, or being rationally incapacitating, or being rooted in anomalous experience-skews an agent's reflective endorsements in such a way that undermines his standing as an autonomous agent.

To anticipate: I suggest that none of these candidate notions can discharge the task assigned to them. My main focus will be on the notions of rational incapacity and of anomalous experience. I argue that the notion of rational incapacity becomes serviceable to the hierarchical theorist only if he relies on a value-laden understanding of what it means to be autonomous. More specifically, I argue that the hierarchical theorist will have to embrace what I call a perfectionist conception of autonomyaccording to which the value of rational capacity is placed at the apex of the axiological network in terms of which self-governance is constituted and assessed-in order to assert that being delusional necessarily undermines personal autonomy. Likewise, I show that construing anomalous experiences through the lens of pathology, and on this basis taking them to undermine an agent's personal autonomy, involves making a significant evaluative decision. If this is right, then given his commitment to articulating a value-neutral conception of personal autonomy, the notions of rational incapacity and of anomalous experience turn out to be unavailable to the hierarchical theorist as a resource for justifying this claim of necessity.

The hierarchical conception of autonomy seems to be the only available way to sustain a value-neutral understanding of self-governance. What the arguments put forward in this paper suggest is that the value-neutral autonomy theorist must concede that being delusional does not necessarily undermine an agent's autonomous standing. Where an agent reflectively endorses his or her delusional experiences, consistently over time and even when clear sighted, the agent counts as autonomous by the lights of the value-neutral theorist's conception of personal autonomy. If this conclusion is deemed unacceptable, then one contribution this discussion makes to the effort of understanding how delusion impairs personal autonomy is to help us pinpoint the ways in which our value commitments inform our judgements of impaired personal autonomy under the condition of being delusional. Alternatively, the considerations to be presented here may compel us to rethink the assumption that being delusional always and necessarily impairs personal autonomy. This would signify a striking and important revision to our understanding of the relationship between serious psychopathology and freedom. In line with much of the philosophical literature in this area, Owen, Freyenhagen et al (2009) assume that the norms of psychiatric practice should be taken as the fixed point and that we should adopt a theory or conception of personal autonomy that anchors and justifies this practice. ${ }^{5}$ To this end, they conclude in favour of a substantive, value-laden conception of autonomy over a procedural, value-neutral one. But this is an assumption that comes under pressure for those who seek to maintain a value-neutral stance in making judgements about personal autonomy and freedom.

\section{Rationality, capacity, and autonomy}


Before turning to the notion of rational incapacity, it would be helpful to begin by addressing the idea that delusions are symptomatic of a mental disease, because much of our thinking about rational capacity in delusion is influenced by this particular conception of delusion. In the General Psychopathology, Karl Jaspers succinctly summarises this picture of psychosis as disease, stating that psychoses spring from disease processes. ${ }^{6}$ Describing this view more recently and with reference to the contemporary debate, Gordon Claridge writes: "Conventional interpretations of psychosis ... are essentially modelled on notions of disease as neurological deficit." ${ }^{\prime 7}$ Importantly, the putative malfunctioning of the brain is envisaged as being so serious as to generate extraordinary disturbances of the mind - disturbances that leave their subjects rationally incapacitated. It is in these terms that psychotic experiences have tended to be interpretatively framed. ${ }^{8}$ The prospect of anchoring psychosis in the notion of rational incapacity caused by biological dysfunction is germane to the present discussion because it holds out the promise of preserving the idea-in naturalistic, valueneutral terms - that being delusional undermines our standing as autonomous agents.

This approach is beset by both empirical and conceptual difficulties. Any biological markers that are found to be systematically correlated with psychosis can only be understood to have autonomyimpairing significance within the context of a theory that explains how psychosis constitutes biological dysfunction and how this biological dysfunction, in turn, erodes a person's capacity for selfgovernance. But there is at present no such biological account of functional psychoses. ${ }^{9}$ In the absence of any account of psychosis-and thus of delusion-as biological dysfunction, it would be vacuous to speak of delusion as a biologically rooted mental disease. So it does not seem possible to rely on biological notions of dysfunction to establish rational incapacitation in functional psychoses. The primary question for the value-neutral autonomy theorist is thus whether, in a delusional state, one's rational capacities per se can be held to be so far impaired as to skew one's reflective endorsements in such a way that undermines one's standing as an autonomous agent. It is to this question that I will now turn. ${ }^{10}$

(a) The gap between rational capacity and personal autonomy

To appreciate the distinctiveness of delusion, it is helpful to note that the term 'psychosis', under which the concept of delusion is subsumed, is a broad one. It includes - disjunctively and in addition to delusions and hallucinations-disorganised thinking and speech, catatonic behaviour, and avolition. ${ }^{11}$ By definition, disorganised thinking rules out the capacity for engaging in deliberation and reflection, a pre-requisite for formulating a viewpoint that is expressive of autonomous agency. Likewise, catatonic behaviour and avolition imply a paucity of agency that is underpinned by reflective commitment, given the paucity of any expression of agency at all. But these criteria are disjunctive to delusions - and delusions themselves, as Jaspers observed a century ago, do not obliterate the delusional agent's critical faculties. Far from it, the agent's rational capacities seem to be sufficiently preserved to be "put into the service of the delusion. The patient thinks, tests arguments, and counterarguments in the same way as if he were well."12 Jaspers adds that a delusional system can be constructed "which in its own context is comprehensible [and is] sometimes extremely closely argued."13

Reviewing the contemporary debate nearly ninety years later, Jose-Luis Bermudez observes that "many delusional schizophrenics ... manage to construct a remarkably consistent and coherent view of the world. Apparently recalcitrant data are fitted into the web of delusional belief, their consequences noted and assimilated." ${ }^{14}$ Thus unlike a person who is delirious or one who suffers severe memory loss, a delusional subject can be capable of engaging in reasoning and forming a distinct viewpoint on the world and on her experiences that she reflectively endorses. Indeed, in the 
case of chronic, stabilised and elaborated delusions, a delusional agent can explain with clarity, internal consistency, and thoughtfulness why she is committed to the delusional outlook. The lucidity of the agent's commitment to this outlook is radically unlike the rapid changes in direction of thought and incoherent reason-giving in delirium. To capture this striking feature of delusional thinking, Bermudez identifies a notion of rationality that is rooted in the concept of consistency, which he terms 'procedural rationality'. ${ }^{15}$ An agent who is procedurally rational has the capacity to reason in accordance with the formal principles of the logic of consistency. Delusional agents who are capable of lucidly articulating their delusional outlook and providing reasons for reflectively endorsing this outlook seem to be rational in this sense, and on the basis of his survey of empirical findings, Bermudez does indeed conclude that a delusional agent can be procedurally rational. ${ }^{16}$

The claim that rational capacities are incapacitated in delusion thus tends to refer to the connection between the concept of delusion, on the one hand, and notions of truth, justification, and evidence, on the other. Indeed, the bizarre character of delusional thinking, combined with a manifest imperviousness of the delusional subject to counter-evidence, is widely taken to be a defining mark of such thinking. ${ }^{17}$ Bermudez notes that although delusional beliefs have been characterised in numerous ways, all accounts "share an emphasis on the imperviousness of delusional beliefs to countervailing evidence, however overwhelming that countervailing evidence might seem to a thirdperson observer." ${ }^{18}$ Bermudez then goes on to summarise the relevance of this feature of delusions to the notion of rational capacities: "It is fairly clear why this should seem a breakdown in rationality. Rational believers must be sensitive to evidential considerations and shifts in the balance of those evidential considerations."19 Bermudez uses the term 'epistemic rationality' to refer to this ability to form and to update our beliefs in light of the evidence available, distinguishing it from procedural rationality. Thus in the context of assessing rational decision-making capacity in delusional subjects, the focus tends to be placed on the notion of epistemic rationality, i.e. on truth- or justificationtheoretic characteristics of delusion. ${ }^{20}$

This notion of rational capacity maps neatly onto substantive conceptions of autonomy that define autonomous agency in terms of an agent's responsiveness to the norms of truth and goodness. ${ }^{21}$ If an essential part of what it means to be an autonomous agent is to be able to revise our beliefs in light of the evidence available to us, then a delusional agent would be straightforwardly precluded from counting as autonomous, given that epistemic irrationality is an essential feature of delusionality. ${ }^{22}$ However, it is less clear how if at all this notion of capacity maps onto value-neutral conceptions of autonomy that are anchored in the notion of reflective endorsement or, as Adrienne Martin puts it, in the notion of "consistency across one's values hierarchy and how one acts in relation to that hierarchy." ${ }^{23}$ Martin points out that capacity defined in terms of epistemic rationality may even be at odds with autonomy conceived in these terms. This point becomes especially apparent in a situation in which an epistemically irrational agent wholeheartedly endorses his delusional outlook. Given his wholehearted commitment, it will not be possible for the agent to abandon the delusion that lies at the heart of that outlook without also sacrificing an important reflective commitment. Take as an example a delusional agent who believes that trees speak to him and experiences a sense of communion with the natural world on this basis. It may not be possible for this agent to revise this (delusional) belief, in accordance with the norms of epistemic rationality, without thereby abandoning his sense of communion with the natural world that he enjoys and wholeheartedly endorses. Since it is not at all obvious that the notion of epistemic rationality is conceptually connected to that of the ability to adopt a reflective stance towards one's lower-order mental states, Martin (who favours this conception of personal autonomy) suggests severing the concepts of rational capacity and autonomy altogether. On Martin's account, an agent who is rationally incapacitated can nonetheless remain autonomous.

Recall, however, that we are considering here the suggestion that the value-neutral autonomy theorist could vindicate the claim that delusions undermine personal autonomy by appealing to the concept 
of impaired rational capacity. The option of severing the concept of rational capacity from that of autonomy, which Martin advocates, is thus unavailable to the value-neutral theorist at this point. This leaves value-neutral theorists with the following challenge: to spell out why, given the hierarchical conception of autonomy, any reflective commitment rooted in gross epistemic irrationality should for this very reason be discounted from being an expression of genuine autonomy.

\section{(b) Perfectionism}

To begin to address this challenge, it is helpful to notice that contained within the challenge is the assumption that gross epistemic irrationality occupies the same justificatory position as delirium, disorganised thinking, and severe memory loss in our schematic understanding of the way serious cognitive impairment undermines personal autonomy. Each of these conditions is assumed to be sufficient for viewing an agent's autonomy as grievously undermined. The failure to achieve autonomous standing is more apparent in the cases of delirium, disorganised thinking, and severe memory loss because a person does not manage to formulate a distinct viewpoint at all, let alone one that is reflectively endorsed. Thus in contrast with the delusional agent, there is not even an appearance of there being someone-an autonomous agent or person-who values and prefers and whom on this basis decides. Nonetheless, in spite of the varying ways in which the conditions on autonomy fail to be satisfied, the overall failure to achieve autonomous standing is taken as read across all these cases. On what grounds then does this claim stand, namely that gross epistemic irrationality occupies the same justificatory position in the ascription of autonomy status as delirium and severe memory loss?

The claim is made intelligible by the value placed by the community on epistemic rationality itself. It is only within a community that places a high premium on epistemic rationality that the idea becomes intelligible that its erosion or absence could constitute a condition that undermines self-governing agency. Moving from intelligibility to a justification, however, involves more than acknowledging that epistemic rationality is deeply valued. It involves according a unique status to epistemic rationality since we are appealing to it in order to withhold the ascription of autonomy status to someone in whom a hierarchy of values is weaved into a recognisable and distinct viewpoint, but who manifests gross epistemic irrationality on account of being delusional. To say of such an agent that she fails to be genuinely self-governing requires, on the part of the community, a commitment to a particular organisation of a range of values, according to which highest value is placed on being epistemically rational.

In practice, organising values in this way would involve taking the value of epistemic rationality to trump other things that we recognise as having great personal significance-including personal fulfilment, finding a sense of purpose and meaning in life, perhaps even spiritual awakening-since delusions, especially ones that are systematic, chronic and elaborated, often become a central organising principle in a person's life and can provide the agent with a sense of personal fulfilment. In certain cases, this happens because the delusion comes to signify a change of perspective for the agent that is spiritually meaningful. ${ }^{24}$ (This is an important point to which I shall return in the final section below).

While there may be good reasons for placing great emphasis on epistemic rationality, prioritising it above all other things it is possible to value is antithetical to conceptions of autonomy that aim at being value neutral. In his exegetical essay on JS Mill's liberalism, Richard Arneson criticises Dworkin's conception of liberalism for prioritising rationality over all other values, stating that rationality is "a value we have no more reason to impose on an adult against his will for his own good than we have reason to impose any other value on paternalistic grounds." ${ }^{25}$ Typically at this point delusions are cited as an exception to this general condition, but this qualification tends to be anchored in the supposition 
that the disease conception of delusions is well established. ${ }^{26}$ Given that this supposition continues to be contested today for good empirical and conceptual reasons (as noted above), it would be rash of the autonomy theorist to privilege the disease interpretation of psychosis over all other interpretations. Without assuming the disease interpretation, however, it is not at all clear that chronic and stable delusions that are reflectively endorsed by their subjects ought to be treated as an exception to the liberal principle articulated by Arneson. Indeed, that is exactly the point that is being pressed here: we have, as yet, no sound rationale for treating delusions as an exception. It may be countered that delusions are so severely epistemically irrational that they wear their pathological mark on their sleeves, as it were. There is no need to prioritise the value placed on epistemic rationality above all other values, in order to insist that a basic degree of epistemic rationality is necessary for the exercise of genuine autonomy, since the delusional agent fails to manifest even this degree of epistemic rationality. But the difficulty with this response, as noted by Martin 2007 (see section above), is that it is not clear in what way epistemic rationality is necessary at all for the exercise of genuine autonomy, conceived of in terms of reflective endorsement.

It seems to me that the only way of making sense of this claim of necessity is to view rationality (this includes epistemic rationality) as an excellence or a virtue that is cultivatable and that ought to be cultivated in agents in order for them to count as truly free and self-governing agents. To be committed to this claim, however, would be to adopt a perfectionist, rather than a prudential, view of autonomous agency - and perfectionism presupposes a value substantive conception of freedom. This point merits elaboration. The terms 'prudential' and 'perfectionist', as I am using them here, are borrowed from the debate about conceptions of well-being, but there is a close analogue between freedom and well-being that makes these terms useful in understanding the pressure placed by this counter-response on the value-neutral conception of autonomy. According to the prudential conception of well-being, an agent is the ultimate (if fallible) authority about how well her life is going for her. Being epistemically rational may not sit at the zenith of an agent's value hierarchy, and this fact will have a bearing both on how she governs herself and on her assessment of her own well-being. Analogously, according to the prudential conception of autonomy, an agent succeeds in governing herself if she lives a life that coheres with-or is expressive of-her most deeply-held values, regardless of what these values happen to be. She is the ultimate (if fallible) authority not just about what matters most to her, but also about what should matter most to her. Summarising the difference between the two conceptions of value (prudential vs perfectionist) with reference to well-being, Larry Sumner writes: "A life has prudential value if it is going well for the individual whose life it is. A life has perfectionist value if it displays the excellences appropriate to the kind of individual whose life it is." 27 Analogously, we may say that an agent is self-governing, by prudential lights, if she is managing to live her life in accordance with her most cherished values. By contrast, an agent is self-governing, by perfectionist lights, if an agent displays the excellences that are essential to self-governance and freedom, excellences that are specified in an agent-independent way (i.e. without reference to what individual agents happen to value).

The gap between epistemic rationality and autonomy, hierarchically construed, can be plugged only by adopting a perfectionist conception of autonomy because it is only by appealing to the notion of epistemic rationality as an excellence that we could begin to see why it is at all relevant to the autonomy-constituting reflective endorsements we make of our lower-order mental states, let alone necessary for it. In effect, we need to view certain instances of reflective endorsement but not others as manifesting human excellence (i.e. human excellence is manifested only in those instances of reflective endorsement that are epistemically rational), and to embed this view within a framework that makes such excellence a precondition on autonomous agency. In moving the locus of authority away from the individual agent and placing it in an ideal standard of freedom, instantiated through a stipulated range of excellences, a perfectionist conception of autonomy ceases to be value-neutral. Thus any justification of the claim that being delusional undermines one's autonomous standing which rests on perfectionist grounds is antithetical to the hierarchical theorist's value-neutral conception of 
autonomy. Without moving the locus of authority away from the individual agent though, it is not at all clear why epistemic rationality is at all relevant, let alone necessary, for governing ourselves by exercising our agency in a manner that is consistent with our most deeply-held values (epistemic rationality simply may not figure in an agent's set of most deeply-held values).

A perfectionist conception of autonomy can also be problematic in a more specific way: if we adopt the perfectionist stance just towards delusional agents alone, and not towards adults generally, the delusional agent suffers from a burden that is asymmetrically and unfairly imposed. Of any two adults who do not seem to prioritise epistemic rationality above all other things in their hierarchy of values, if just one of the two adults is deemed to be delusional, it would be unjust to demand a perfectionist standard of (and thus to withhold the ascription of autonomy status to) the delusional adult only. But the demand for a perfectionist standard across the board is precisely what value-neutral autonomy theorists reject.

Against this more specific worry about double standards, it may be argued that the degree of irrationality in a delusional outlook is distinctively severe and in this way serves to mark out the delusional agent from agents who manifest epistemic irrationality but are not deemed delusional. In other words, the suggestion here is that the irrationality manifest in delusions is significantly more capacity-impairing than the various forms of irrationality that non-delusional agents ordinarily manifest, which explains why the epistemic irrationality instantiated in the former case does undermine an agent's autonomous standing, whereas it does not in the latter case. In sum, this move consists in the adoption of a perfectionist view of autonomy but seeks to contain the perfectionist standard just to delusional agents, whilst retaining a value-neutral conception of autonomy in the case of non-delusional (normal) agents, in a manner that is consistent and fair. The question I now want to consider is whether there are principled reasons for this containment.

\section{(c) Epistemic irrationality in delusions and in ordinary life}

In order to move from the observation that delusional individuals are epistemically irrational to the conclusion that their capacity to self-govern is undermined by this fact, it is vital to establish that nondelusional individuals are not similarly irrational since it is normally granted that the latter are selfgoverning agents. As it turns out, there are strong empirical grounds for holding that ordinary (nondelusional) adults are just as disposed as delusional adults to manifest errors in reasoning that violate epistemic and procedural norms. That is to say, both delusional and non-delusional adults are disposed to manifest epistemic irrationality. If the severity of epistemic irrationality is matched across the delusional group and at least some members of the non-delusional group, then the fact of their epistemic irrationality would not constitute grounds for withholding the ascription of autonomous agency to individuals in the delusional group, whilst we continue to view epistemically irrational individuals in the non-delusional group as autonomous.

So are delusional individuals systematically more epistemically irrational than at least some nondelusional individuals? This contention does not seem to be borne out by available empirical evidence. Reviewing the patterns of epistemic irrationality observed in delusional individuals, Bermudez identifies three prominent patterns:

1. It is characteristic of delusional patients not to entertain the possibility that the delusional belief might be false.

2. Delusional patients either fail to engage in such a search [for evidence] or filter out any nonconfirmatory evidence. ${ }^{28}$

3. Delusional patients are notoriously poor at considering the probability of the datum to be explained in the absence of the explanatory factor put forward. ${ }^{29}$ 
All three patterns have been observed in the non-clinical population too, most notoriously in the confirmation bias. ${ }^{30}$ Furthermore, in the non-clinical population, these patterns are observed not just in the case of mundane and unsurprising beliefs, but also in the case of bizarre ones too. ${ }^{31}$ Now, the bizarre beliefs that non-delusional individuals can sometimes hold with rigidity-impervious to counterevidence-have been hypothesised to stem from a person's emotional needs..$^{32}$ This raises an interesting question about the way we conceive of freedom in relation to beliefs that are tenaciously held. Whether or not the specific hypothesis about emotional needs turns out to be true, there seems to be an asymmetry in our judgements of personal autonomy between, on the one hand, someone in the nonclinical population who tenaciously holds on to a belief because of an emotional need (or other predisposing factor), and on the other hand, a delusional person who does so. Both agents manifest epistemic irrationality in Bermudez's sense, and at least in certain cases do so to the same degree. Why then do we take the delusional person to be in the grip of the delusion in such a way that undermines his agency, whilst not viewing the ordinary (nonclinical) person as being in the grip of an emotional need in a similarly autonomy-undermining way? Without presupposing the disease conception of psychosis, this asymmetrical judgement seems an arbitrary one to make. ${ }^{33}$

A further possibility for the hierarchical theorist is to appeal to the non-ordinary or anomalous states of consciousness that are taken to be essential to the formation and maintenance of delusions, in order to establish (in value-neutral terms) the claim that delusions skew one's reflective endorsements in such a way that undermines one's standing as an autonomous agent. This option will be explored next.

\section{Anomalous experiences in delusion}

Brendan Maher has long argued that delusional beliefs are rational inferential responses to anomalous experiences. ${ }^{34}$ Jaspers a century ago similarly insisted that what is primary in delusional ideation is not the truth-value of the delusion (nor its often bizarre character), but rather the "transformation in the subject's total awareness of reality," the notion of awareness here being construed experientially. ${ }^{35}$ The salience dysregulation hypothesis-currently an influential way of understanding what happens experientially in psychosis, especially schizophrenic psychosis-corroborates the Jaspers-Maher view of the primacy of anomalous experiences in delusion formation and maintenance. ${ }^{36}$

Could the claim that delusions undermine a person's autonomous standing be justified by appealing to this experiential aspect of delusions? Some authors have attempted to establish the claim in this way, doing so by appealing to anomalous experiences that invoke negative affective responses (for instance, a subject feels watched and starts to feel threatened, or a subject begins to feel as though she is dissolving-becoming physically insubstantial-and panics as a result). Both the distress experienced by the subject and the reflective disavowal that ensues provide grounds for just such a justification. Thus drawing on Elyn Saks' memoir (in which Saks describes responding to anomalous experiences in this way), Mackenzie and Poltera (2010) suggest that mental illness impairs capacities required for what they call self-narrative construction, i.e. the capacity to integrate one's selfexperience into a coherent self-narrative. This forms the basis for the authors' claim of impaired autonomy in mental illness. ${ }^{37}$

But not every delusional agent suffers a loss of this capacity for integration (whether through selfnarrative or by other means). On the contrary, anomalous experiences seem sometimes to facilitate an enhanced sense of being integrated, as shown in the qualitative study conducted by Glenn Roberts (op. cit.). Another example, reported by Lukoff (1985), captures this possibility succinctly:

Throughout her [psychiatric] hospitalization, another person in the midst of a similar [psychotic] episode told the staff, "Listen ... I've had this incredible mystical experience." 
Today she writes, "Now, more than eight years later, I can look back and say, 'Listen .... I had this incredible mystical experience.' It integrated and made sense of everything that had ever happened to me or that I had ever done. It showed me the meaning and purpose of life. It was a birth into a state of consciousness I did not even know existed, but which is now a permanent part of my life." 38

This divergence in possibilities suggests that it is not the fact of the anomalous experience itself, but rather the distress that can be associated with such experiences, and the subject's response to this, that results in impaired autonomy. The impairment here may be due to the experience of distress that is reflectively disavowed, as well as the obstruction that this poses to an agent's capacity for integration (through whatever means), as just noted. The value-neutral autonomy theorist can embrace this account of how autonomy is impaired in a delusional state, but this account refers to the state's distressing quality, rather than its delusional quality, since delusion in and of itself isn't necessarily distressing. Furthermore, this fact about distress is not unique to mental illness: any distress, if severe enough, can disorientate a person and unravel the threads of a self-narrative that served her well up to that point - whether this distress is caused by physical/mental illness, or by significant personal loss, for instance. To anchor the claim that delusions undermine personal autonomy, it would have to be shown that it is the anomalous experience itself, rather than the concomitant distress that can accompany it, that impairs an agent's autonomy.

Once the delusional outlook, based in anomalous experience, is disentangled from the distress condition however, it is not clear that an appeal to anomalous experience itself can be used to ground the claim of impaired autonomy in delusional agents. It is a familiar point that the significance of experience, anomalous or otherwise, stands open to interpretation, ${ }^{39}$ and so it should come as no surprise to discover that anomalous experiences can shape the course of human lives in such a variety of ways. One important way in which this familiar point shows up in the context of delusions is in the difficulty of disambiguating so-called psychotic experiences from purportedly spiritual or mystical ones. ${ }^{40}$ Exploring this difficulty from a neutral standpoint is not easy, but a helpful way in is by noticing that phenomena such as hallucinations ${ }^{41}$ and delusions ${ }^{42}$ occur with surprising frequency in the nonclinical population - and these anomalous experiences are sometimes reported as playing an adaptive role in the lives of the individuals who experience them. By the lights of recent DSM editions, these individuals in the nonclinical population would count as psychotic since the diagnostic criteria for psychotic illnesses such as schizoaffective disorder and schizophreniform disorder require just two experiential features deemed psychotic (delusions and hallucinations), present for a duration of at least two weeks and a month respectively, and requiring no impairment in social/occupational functioning. Thus according to these criteria, it is possible for a highly functional individual to end up counting as diagnosable with a psychotic illness on account of experiencing hallucinatory and delusional experiences for an extended period of time (as those with chronic, stable, and elaborated delusional systems do). ${ }^{43}$ The crucial question here is whether the DSM criteria effectively stipulate that all anomalous experience of delusional and hallucinatory varieties must be viewed through the lens of psychopathology, a stipulation that overlooks available alternative interpretations of these experiences and is thus open to the charge of being overly inclusive.

There are two variants of this worry worth distinguishing from each other:

(1) The criteria used to determine that delusions are pathological seem also to capture valid spiritual experiences.

(2) Of any given anomalous experience, it is often difficult to determine whether it is psychotic (thus pathological) in character or whether it is instead a spiritual or a mystical experience.

Beauchamp and Childress register the first challenge in their discussion of the concept of autonomy, ${ }^{44}$ and Stanislav Grof expresses this worry about the over-inclusivity of the DSM criteria for psychosis in the following terms: "Mainstream psychiatrists are unable to see a difference between psychospiritual 
crises, or even uncomplicated mystical states, and serious mental illness, because of their narrow conceptual framework." ${ }^{\prime 5}$

The second variant of the worry points to the indeterminate nature of anomalous experiences relative to the significance it is possible to ascribe to them. One reason why it is difficult to determine the character of an anomalous experience-as pathological or non-pathological-is that such experiences are often very similar across both categorisations, in form and in content. ${ }^{46}$ Another reason for the difficulty in distinguishing pathological from non-pathological anomalous experiences, alluded to a moment ago, is the fact that anomalous experiences do not necessarily give rise to distress. Freeman and Garety have found that rather than being associated directly with the anomalous experience itself, distress arises depending on how the individual makes sense of this experience, i.e. her appraisals. ${ }^{47}$ Separately, Grof - who coins the term 'spiritual emergency' to refer to experientially difficult stages of spiritual opening and of a radical personality transformation - suggests that a subject's attitude to this crisis and her experiential style significantly determines the course of the experience as it unfolds in time. Those who are open to "experiential work and interested to try it" may, Grof suggests, interpret these anomalous experiences as signifying a psychospiritual crisis out of which can develop "psychosomatic health, increased zest for life, a more rewarding life strategy, and an expanded worldview that includes the spiritual dimension of existence." ${ }^{48}$ The observation made by Freeman and Garety, and separately by Grof, is corroborated by findings in a qualitative study conducted by Jackson and Fulford (1997). The authors conclude:

The cases reported in the present study [cases of nonclinical individuals who have had anomalous, psychotic-like experiences] show ... that psychotic phenomena may be, in and of themselves, good. And whether they are spiritual (good) or pathological (bad) depends ultimately not on some subtlety of their phenomenology (the focus of traditional psychopathology), but on the way in which they are embedded in the structure of values and beliefs by which the actions of the subjects concerned are defined. In the case of pathological psychotic phenomena, there is a radical failure of action. ... In the case of spiritual psychotic phenomena, action is radically enhanced. ... Instead of there being "literally no action" (Fulford 1989, ch.10), the individual is empowered. ${ }^{49}$

If the significance of anomalous experience-or a subset thereof-is interpretatively porous, being open at least to either a pathological or a spiritual interpretation, then the prioritisation of the medical interpretation over alternative interpretations stands in need of a justification. Seen from the perspective of theorists of autonomy who wish to remain impartial to this interpretative debate, the inclusion of delusions/hallucinations in the diagnostic criteria for psychotic conditions would appear to presuppose rather than to establish the pathological nature of these anomalous experiences. The circularity here is problematic: it gives rise to the worry that any anomalous experience could be judged pathological merely by the inclusion of that experience type in the diagnostic criteria for a mental disorder - a problem underscored by the history of the conceptualisation of homosexuality as a mental illness. (Cf Craigie 2011 for an analogous concern about the diagnostic criteria for anorexia nervosa)..$^{50}$ Avoiding this circularity requires us to adopt an interpretatively neutral stance according to which anomalous experiences are not automatically read as pathological. This points us to the following conclusion: the claim of impaired autonomy in delusional agents cannot be grounded in an appeal to anomalous experience given the interpretative porousness of such experience and the availability of several interpretative possibilities, just one of which casts it as pathological.

In addition to this worry about circularity, the threat of perfectionism lurks here too. The interpretative debate about the significance of anomalous experience underscores the fact that such experience-especially ones that are termed delusional-can contribute to a person's sense of purpose and existential meaning, enabling her to feel subjectively fulfilled and therein to enjoy newfound wellbeing. ${ }^{51}$ The general assumption that epistemic rationality and existential meaning are 
at least mutually complementary, if not deeply intertwined, thus seems to break down here - and unless we are perfectionists about personal autonomy, it is not obvious that greater value should be placed on epistemic rationality than on existential meaning. To put this last point more precisely: it is not obvious that someone who places greater value on existential meaning than on epistemic rationality should, for this reason, be deemed not to have the capacity to govern herself and to direct her life in accordance with her most deeply held values. ${ }^{52}$

Having surveyed the most prominent candidates for connecting the concepts of delusion and impaired autonomy in general terms-i.e. disease, incapacity due to irrationality, and anomalous experienceand found that none readily provides a value-neutral justification for the claim that the condition of being delusional itself undermines an agent's autonomy, it might be useful to consider the implications of this conclusion for the notion of authenticity. For closely related to the picture of the delusional subject being held in the grip of psychosis is the idea that psychosis is an entity that is necessarily external to the subject - and thus, that even if a delusional outlook is reflectively endorsed, it remains an inauthentic commitment on the part of its subject. In order for this idea to stand, we need a way of demarcating the boundary between what is properly internal to the self and what is external to it. If the conceptualisation of psychosis as a disease were a well anchored one, this would provide us with a promising route, given the familiar notion of disease as an entity that is external to the self. But we have seen that there is no conclusive grounds for this conceptualisation of psychosis. The appeal to irrationality is likewise unpromising given that it threatens to encompass instances of irrationality in non-delusional and delusional agents alike. This may not matter from the perspective of a long-standing tradition of viewing a person's disposition to be irrational as an external force that directs the person's choices, a disposition that is "alien to the self." ${ }^{33}$ But as Arneson points out, this tradition presumes the prioritisation of rationality above all other values, a hierarchical organisation that we have no reason to suppose is universally endorsed. Value-neutral theorists should hence be cautious about equating inauthenticity with irrationality. In cases where a delusional subject reports deeply valuing her delusional outlook, there thus appears to be no way to separate the delusional outlook from the true self, such that the outlook can be said to be external to this self. But without a criterion by which to demarcate the boundaries of the self-and to place psychosis firmly outside the self-the assumption that a reflectively endorsed delusional outlook is inauthentic remains unsupported. Indeed, if anything, an agent's reflective endorsement of a delusional outlook seems more authentic than ordinary endorsements, because of the intersubjective resistance faced by delusional agents and the depth of commitment they demonstrate to this outlook in having to navigate this resistance (no threat of brain-washing or social conditioning here).$^{54}$

\section{Conclusion}

The purpose of this paper has been to underscore the elusiveness of a value-neutral characterisation of the claim that being delusional necessarily undermines our ability to live our lives by our own lights, to govern ourselves in accordance with what each of us most deeply values. We continue to wish for two things, which turn out to be inconsistent if the foregoing considerations are accepted:

(a) Firstly, that we can conceive of other people as being autonomous even if we disagree with each other over what matters most - that is, that there is a value-neutral conception of personal autonomy available for us; and

(b) Secondly, that being delusional (a psychotic state that lies at the heart of traditional psychopathology) necessarily impairs our ability to exercise autonomy. 
These two wishes sustain the ideal of articulating a non-paternalistic account of how human autonomy can be impaired by psychosis. The challenge is to explain how Claim (b) is true, and the hope is that we will be able to employ the conception of autonomy in Claim (a) to explain the truth of Claim (b) in value-neutral terms. To date, no attempt at articulating such an account has been forthcoming (see e.g. Hope 2004 and Szmukler 2016). ${ }^{55}$ The diagnosis offered in this paper for the elusiveness of a nonpaternalistic account is this: the hierarchical theorist's value-neutral conception of autonomy identifies the locus of autonomy in an agent's sense-making activities, i.e. in our attempt to interpret our experiences in light of our values. Being delusional does not put a stop to sense-making. Humans carry on trying to make sense of their experiences even when diagnosed as delusional, and they can do so with remarkable coherence and clarity.

It may be true that what we most deeply value may change as a result of having a psychotic mental disorder, but this alone isn't grounds for saying that our personal autonomy is impaired by this serious mental illness. Other life-transforming conditions such as losing a loved one or becoming a parent can also bring about a change in our sense of self and what we most deeply value, and here we haven't the least inclination to say that bereavement or parenthood necessarily impairs our autonomy. So we will need to find something unique to the nature of delusion that has this debilitating effect, to establish that being delusional necessarily impairs personal autonomy, but the only way to do this seems to involve an appeal to our substantive values. Should we find such an appeal unacceptably paternalistic, then we must begin to see delusional agents in a new light, i.e. seeing that, in and of itself, being delusional does not preclude an agent from being autonomous and free. To quote Henry Cockburn, diagnosed with schizophrenia in his early twenties, "I think I just see the world differently from other people, and maybe if psychiatrists understood this, I would not have been in the hospital." ${ }^{56}$ If we wish to remain steadfastly non-paternalistic and committed to a value-neutral framework for personal autonomy, the foregoing considerations presented in this paper suggest that we would have to concede this: Henry Cockburn sees the world differently from other people, but this in itself doesn't make him any less autonomous than the rest of us.

\section{Acknowledgements}

I would like to thank two anonymous referees for this journal for extremely incisive and helpful comments on an earlier iteration of this paper. 
${ }^{1}$ This conception of autonomy has been most prominently articulated and defended by Harry Frankfurt. See 'Freedom of Will and the Concept of a Person,' Journal of Philosophy 68,1 (1971): 5-20 and The Importance of What We Care About (Cambridge: Cambridge University Press, 1988)

2 Throughout, I shall use the terms 'autonomy' and 'self-governance' interchangeably.

${ }^{3}$ Eric Matthews expresses this idea as follows: "A person [with a mental disorder] may either fail altogether to form a coherent personal identity based on reflection on his or her own experiences, or else (more likely) may suffer disruption to an identity already formed in this way. In the latter case, the person may have an identity, but one which is 'disturbed' in that it is not the natural outcome of inner, personal reflection, but is caused by something else, either brain damage or factors of various sorts (social, psychological) which disrupt the normal process of human development": Eric Matthews, 'Autonomy and the Psychiatric Patient', Journal of Applied Philosophy, 17,1 (2000): 59-70

${ }^{4}$ One example of this is provided by a man named Rod Harvey, who has been diagnosed with manic depression since the late 1980s, and who wholeheartedly and consistently endorses the experiences deemed psychopathological as he enjoys a sense of aliveness and communion (with angels) in these experiential states. His reflective endorsement is expressed verbally, but also in his decision to limit his intake of mood stabilizing medication. The latter choice is especially remarkable because he is prone to behave in ways that are risky to himself when he is in a manic state, a point which he fully recognises (and accepts) in view of the twenty years of living with the diagnosis. In a television interview, Harvey is asked whether he regrets being born with manic depression, to which he replies unequivocally, "It's a very easy question; there's a very easy answer: no. Not for a second. Because if you have walked with angels, all the pain and suffering is well worthwhile." This unequivocal statement of what he holds to be of deepest value is striking in its consistency and duration. Harvey understands his life to be profoundly shaped by delusional experiences that are deemed by others to be pathological. Harvey expresses this view in Ross Wilson (2009) Stephen Fry: The Secret Life of the ManicDepressive, United Kingdom: British Broadcasting Corporation.

${ }^{5}$ Owen, Freyenhagen et al. 'Mental Capacity and Decisional Autonomy', Inquiry 52,1 (2009): 79-107

${ }^{6}$ Karl Jaspers, General Psychopathology (Baltimore, Maryland: John Hopkins University Press, 1997), p.575

7 See Gordon Claridge, 'Spiritual Experience: Healthy Psychoticism?" in I. Clarke (ed) Psychosis and Spirituality: Consolidating the New Paradigm ( $2^{\text {nd }}$ ed) (Chichester, UK: Wiley-Blackwell, 2010), p.86

${ }^{8}$ See Emmanuelle Peters, 'Are Delusions on a Continuum? The Case of Religious and Delusional Beliefs', in I. Clarke (ed) Psychosis and Spirituality: Consolidating the New Paradigm ( $2^{\text {nd }}$ ed) (Chichester, UK: WileyBlackwell, 2010), pp.127-138

${ }^{9}$ See Davies and Coltheart, 'Introduction' in Davies and Coltheart (eds) Pathologies of Belief (Oxford: Blackwell, 2000), pp.1-46, and Freeman and Garety, 'Connecting Neurosis and Psychosis: The Direct Influence of Emotion on Delusions and Hallucinations', Behaviour Research and Therapy 41 (2003): 923-947. The history of the debate about the reality of mental illness points to the conclusion that non-reducible evaluative judgements seem to figure essentially in our concepts of psychopathology, including that of the complex notion of psychosis.

${ }^{10}$ To be clear: the absence of any biological account of delusion blocks the idea that rational incapacity is pathological when instantiated in a delusional agent, but not when instantiated in non-delusional agents, because delusion is a biological disease. This paves the way for the discussion in the next section, in which I shall address the notion of rational incapacity on its own terms, exploring the suggestion that the ascription to delusional agents of impaired personal autonomy be made on the basis of rational incapacity.

${ }^{11}$ See American Psychiatric Association (APA), Diagnostic and Statistical Manual of Mental Disorders. 5th ed. (Washington, DC: American Psychiatric Association 2013), Schizophrenia Spectrum and Other Psychotic Disorders, Criteria A. That this distinction between the different conditions subsumed under the umbrella term 'psychosis' is not merely of theoretical interest, but one that is also empirically useful, is borne out by the fact that there are delusional individuals with a diagnosis of schizophrenia who are able to concentrate on a diverse range of topics and are able to communicate in ways that are comprehensible to others. See E. Jones and P. Watson, 'Delusion, the Overvalued Idea, and Religious Beliefs: A Comparative Analysis of their Characteristics," British Journal of Psychiatry 170 (1997): 385. A more recent empirical study found that amongst the very seriously ill - those detained under the UK Mental Health Act (1983, revised 2007)-there were individuals who were deemed to retain capacity, as this is defined by the UK Mental Capacity Act 2005. These findings were reported in Owen, Szmukler et al, 'Mental Capacity and Psychiatric In-Patients: 
Implications for the New Mental Health Law in England and Wales', British Journal of Psychiatry 195 (2009): 257-263

12 Karl Jaspers op.cit., 97

${ }^{13}$ Karl Jaspers op. cit, 106

${ }^{14}$ See J.L. Bermudez, 'Normativity and Rationality in Delusional Psychiatric Disorders', Mind and Language 16,5 (2001): 471

${ }^{15}$ For an early use of this term, see H.A. Simon, 'From Substantive to Procedural Rationality' in S. J. Latsis (ed), Method and Appraisal in Economics (Cambridge: Cambridge University Press 1976), pp. 130-131

${ }^{16}$ J.L. Bermudez op. cit, 471

${ }^{17}$ See APA, op.cit., and Karl Jaspers op. cit. In the DSM-V, delusions are characterised firstly as "fixed beliefs that are not amenable to change in light of conflicting evidence." (APA op. cit., p.87)

${ }^{18}$ See J.L. Bermudez, op. cit., 462

19 See J.L. Bermudez, op. cit., 462

${ }^{20}$ See Adrienne Martin, 'Tales Publicly Allowed: Capacity, Competence, and Religious Belief', Hastings Center Report 37,1 (2007), 37. See also E Saks and S Behnke, 'Competency to Decide on Treatment and Research: MacArthur and Beyond', Journal of Contemporary Legal Issues 10 (1999), 119

${ }^{21}$ See Susan Wolf, Freedom Within Reason (Oxford: Oxford University Press 1990)

${ }^{22}$ Wolf's substantive account of personal autonomy is designed precisely to justify the claim that delusions undermine our free agency and autonomy, so the neat alignment between the concepts of epistemic irrationality, capacity, and autonomy is not a coincidence. For a development of this point, see Susan Wolf, 'Sanity and the Metaphysics of Responsibility', in Schoeman (ed.), Responsibility, Character, and the Emotions: New Essays in Moral Psychology (Cambridge, UK: Cambridge University Press 1987), 46-62

${ }^{23}$ See Adrienne Martin, op. cit., 38

${ }^{24}$ See G. Roberts, 'Delusional Belief Systems and Meaning in Life: A Preferred Reality?', British Journal of Psychiatry 159 supplement 14 (1991), 19-28 and M. Jackson and K.W.M. Fulford, 'Spiritual Experience and Psychopathology', Philosophy, Psychiatry, Psychology 4,1 (1997): 41-65

25 See Richard Arneson, 'Mill versus Paternalism,' Ethics 90,4 (1980): 474

${ }^{26}$ As sketched out above, delusions according to this particular conception are extraordinary disturbances of the mind that are rationally incapacitating and that are caused by serious malfunctioning in the agent's nervous system.

${ }^{27}$ See Larry Sumner, 'The Subjectivity of Welfare', Ethics 105, 4 (1995): 788

${ }^{28}$ It is not altogether true that delusional agents do not engage in a search for evidence. In his suggested sequence involved in the formation of delusion, Brendan Maher identifies an iterative search procedure stage that is involved in hypothesis testing. See Brendan Maher, 'Anomalous Experience and Delusional Thinking: The Logic of Explanations' in Oltmanns and Maher (eds), Delusional Beliefs (John Wiley and Sons 1988), pp. 1532

${ }^{29}$ See J.L. Bermudez, op. cit., 474-5

${ }^{30}$ Anderson et al 1980 report: "People often cling to their beliefs to a considerably greater extent than is logically or normatively warranted ... initial beliefs may persevere in the face of a subsequent invalidation of the evidence on which they are based, even when the initial evidence is as weak and inconclusive as a single pair of dubiously representative cases." See Anderson et al, 'Perseverance of Social Theories: the Role of Explanation in the Persistence of Discredited Information', Journal of Personality and Social Psychology 39,6 (1980): 1037-1049. For further discussion, also see R. Nickerson, 'Confirmation Bias: A Ubiquitous Phenomenon in Many Guises', Review of General Psychology 2,2 (1998): 175-220, B. Maher, 'Delusions', in Adams and Sutker (eds), Comprehensive Handbook of Psychopathology (New York: Kluwer Academic 2001), pp. 309-339, and S. Sutherland, Irrationality: The Enemy Within (London: Pinter and Martin Ltd. 2013) ${ }^{31}$ The bizarreness of such beliefs suggests that the depth of epistemic irrationality manifested by non-clinical individuals can, at least sometimes, be comparable to the clinical population. To clarify: the notion of the depth of irrationality manifest by a person's belief can be interpreted in several ways, but two ideas commonly associated with it are the degree of a belief's bizarreness and its scope, i.e. the extent of a person's life over which the belief has a hold (at one extreme, it may be a central organising belief; and the other, it may be entirely peripheral to a person's life). Working on the assumption that the more bizarre a (false) belief it is, the more readily available is the counterevidence, and thus the more tenaciously it must be held by the subject in the face of this counterevidence (i.e. the greater the irrationality that is manifest in so doing), my point in observing that epistemic irrationality is observed in the non-clinical population with respect to bizarre beliefs (not just mundane ones) is to suggest that the depth of epistemic irrationality manifest across clinical and (a subset of) non-clinical populations may be comparable. Careful empirical investigation comparing the two 
groups-psychotic subjects and non-psychotic subjects who tenaciously hold bizarre beliefs - will help establish the truth or otherwise of what seems to be suggested by the bizarre character of the beliefs held across both groups. For examples of bizarre beliefs held by non-clinical subjects, see T. Roszak, 'In Search of the Miraculous: Science Joins the Occult', Harper's Magazine (January 1981) and M. Shermer, Why People Believe Weird Things: Pseudoscience, Superstition, and Other Confusions of Our Time (London: Souvenir Press 2007)

32 See M.Shermer, op. cit.

${ }^{33}$ The following possibility is worth noting: the tenacity with which a delusion is held may turn out to rest not on its putative psychotic nature (or at least, not always so), but rather on general features of human belief formation and maintenance. Beliefs that are personally significant tend to be held with absolute conviction (Brett 2002), and chronic delusions tend to involve beliefs that are personally significant (Van Putten 1968, Roberts 1991). So delusions may be held with absolute conviction not on account of their being a delusion, but more simply on account of their being personally significant to the subject whose delusion it is. See $\mathrm{C}$. Brett, 'Psychotic and Mystical States of Being: Connections and Distinctions', Philosophy, Psychiatry and Psychology 9 (2002): 324; van Putten et al., 'Drug Refusal in Schizophrenia and the Wish to be Crazy' Archive of General Psychiatry 33 (1976), 1443-1446; and G. Roberts, op. cit.

${ }^{34}$ Brendan Maher has argued for this view in various places. See for instance B. Maher, 'Delusional Thinking and Perceptual Disorder', Journal of Individual Psychology 30,1 (1974): 98-113, and 'Delusions: Contemporary Etiological Hypotheses', Psychiatric Annals 22,5 (1992): 260-268

${ }^{35}$ See Karl Jaspers, op. cit., p.106

${ }^{36}$ For an overview of the salience dysregulation hypothesis, see Kapur, 'Psychosis as a State of Aberrant Salience: A Framework Linking Biology, Phenomenology, and Pharmacology in Schizophrenia', American Journal of Psychiatry 160 (2003): 13-23

${ }^{37}$ See C. Mackenzie and J. Poltera, 'Narrative Integration, Fragmented Selves, and Autonomy', Hypatia 25,1 (2010): 31-54, and E. Saks, The Center Cannot Hold (Hyperion Books 2008)

38 See D. Lukoff, 'The Diagnosis of Mystical Experiences with Psychotic Features', The Journal of Transpersonal Psychology 17,2 (1985): 177

${ }^{39}$ Early $20^{\text {th }}$ century philosophers, both in the American pragmatist and the European phenomenological traditions, have explored this point at great length.

${ }^{40}$ See Simon McCarthy-Jones, Hearing Voices: The Histories, Causes, and Meanings of Auditory Verbal Hallucinations (Cambridge, UK: Cambridge University Press 2013), p.5

${ }^{41}$ See J. van Os et al., 'Strauss (1969) Revisited: A Psychosis Continuum in the General Population?' Schizophrenia Research, 45,1-2 (2000): 11-20

${ }^{42}$ See M. Jackson and K.W.M. Fulford, op. cit.

${ }^{43}$ See APA, op. cit. and T. Ban, 'Evolution of Diagnostic Criteria in Psychosis' Dialogues in Clinical Neuroscience 3,4 (2001): 257-263

${ }^{44}$ See Beauchamp and Childress, Principles of Biomedical Ethics ( $7^{\text {th }}$ edition) (Oxford: Oxford University Press 2013): 117

45 See Stanislav Grof, Psychology of the Future (New York: SUNY Press 2000): 137

${ }^{46}$ See Karl Jaspers, op. cit. See also A. Boison, The Exploration of the Inner World (New York: Willett, Clark \& Company 1936); P. Buckley, 'Mystical Experience and Schizophrenia', Schizophrenia Bulletin 7,3 (1981): 516521; D. Lukoff and H. Everest, 'The Myths in Mental Illness', The Journal of Transpersonal Psychology 17,2 (1985): 123-153; M. Jackson and K.W.M. Fulford, op cit.; and J. Parnas and M.G. Henrikson, 'Mysticism and Schizophrenia: A Phenomenological Exploration of the Structure of Consciousness in the Schizophrenia Spectrum Disorders', Consciousness and Cognition 43 (2016): 75-88

${ }^{47}$ See P. Garety and D. Freeman, 'Cognitive Approaches to Delusions: A Critical Review of Theories and Evidence', British Journal of Clinical Psychology 38 (1999): 113-154. See also M. Jackson, 'The Paradigm-Shifting Hypothesis: A Common Process in Benign Psychosis and Psychotic Disorder', in I. Clarke (ed) Psychosis and Spirituality: Consolidating the New Paradigm (2 ${ }^{\text {nd }}$ ed) (Chichester, UK: Wiley-Blackwell, 2010).

${ }^{48}$ See Stanislav Grof, op. cit.

${ }^{49}$ See M. Jackson and K.W.M. Fulford, op. cit., p. 55 (emphasis in original)

${ }^{50}$ See J. Craigie, 'Competence, Practical Rationality, and What A Patient Values', Bioethics 25,6 (2011): 326-333

${ }^{51}$ Again, see M. Jackson and K.W.M. Fulford, op. cit., and G. Roberts, op. cit. That anomalous experiences can occupy a position of central prominence in a person's life underscores the importance to this debate of Arneson's reminder, viz. "The more important to the agent the desire that an autonomy-restricting interference frustrates, the greater the loss of autonomy." See Richard Arneson, op. cit., p. 475 
${ }^{52}$ This is not to say that the hierarchy of values is intentionally chosen. It is seldom the case, even in the ordinary population, that an agent sets out his values in an enumerative way and explicitly orders them hierarchically. More often than not, values are revealed through the choices a person makes, or is forced to make in a dilemma. Thus, in the case of valuing a delusional outlook, it is possible to discern this hierarchy in the decision not to take psychotropic medication (van Putten et al 1976), and in affirmation of the delusional outlook through counterfactual imagining (as reported by Roberts 1991).

${ }^{53}$ See Richard Arneson, op. cit., p. 489

${ }^{54}$ Responding to Susan Wolf, Harry Frankfurt explicitly rejects positioning irrational forces as antithetical to freedom, insisting that someone whose life is warped by irrational forces may nonetheless be free, even if this life is deemed by us to be in some way deficient. See Harry Frankfurt, 'Reply to Susan Wolf', Buss and Overton (eds), Contours of Agency: Essays on Themes from Harry Frankfurt (Cambridge, MA: MIT Press 2002), pp.251-2. ${ }^{55}$ See Tony Hope, Medical Ethics: A Very Short Introduction (Oxford: Oxford University Press 2004) and George Szmukler, 'We should replace conventional mental health law with capacity-based law', British Journal of Psychiatry 209,6 (2016):449-453

${ }^{56}$ See H. Cockburn and P. Cockburn, 'The Interview with Carrie Gracie'. London: BBC.

http://www.bbc.co.uk/programmes/p00d9fld (last retrieved 13.11.2018). See also H. Cockburn and P.

Cockburn, Henry's Demons (London: Simon and Schuster UK 2011) 